\title{
Disorders of Calcium Metabolism: Hypocalcemia and Hypercalcemia
}

Mohammad Tinawi ${ }^{1,2}$

1. Medicine, Indiana University School of Medicine Northwest-Gary, Gary, USA 2. Nephrology, Nephrology Specialists, Munster, USA

Corresponding author: Mohammad Tinawi, mtinawi@gmail.com

\section{Abstract}

Calcium $\left(\mathrm{Ca}^{+2}\right)$ is a divalent cation that plays a critical role in numerous body functions such as skeletal mineralization, signal transduction, nerve conduction, muscle contraction, and blood coagulation.

$\mathrm{Ca}^{+2}$ metabolism is linked to magnesium $\left(\mathrm{Mg}^{+2}\right)$ and phosphate metabolism. $\mathrm{Ca}^{+2}$ homeostasis is dependent on intestinal absorption, bone turnover, and renal reabsorption. The hormonal regulators of these processes are the parathyroid hormone $(\mathrm{PTH})$, calcitriol $\left\{1,25\right.$-dihydroxyvitamin $\left.\mathrm{D}\left[1,25(\mathrm{OH})_{2} \mathrm{D}\right]\right\}$, and serum ionized

$\mathrm{Ca}^{+2}$. Cloning of the $\mathrm{Ca}^{+2}$-sensing receptor (CaSR) has greatly advanced the understanding of $\mathrm{Ca}^{+2}$ metabolism. Disorders of $\mathrm{Ca}^{+2}$ metabolism are easily recognized because $\mathrm{Ca}^{+2}$ is included in routine chemistry panels. Measurement of ionized $\mathrm{Ca}^{+2}$ is the preferred way to ascertain the diagnosis of hypocalcemia and hypercalcemia.

Categories: Endocrinology/Diabetes/Metabolism, Internal Medicine, Nephrology

Keywords: hypocalcemia, hypercalcemia, electrolyte disorders, calcium metabolism, calcium sensing receptor

\section{Introduction And Background}

\section{Forms of serum calcium}

Normal total serum calcium $\left(\mathrm{Ca}^{+2}\right)$ concentration is $8.8-10.4 \mathrm{mg} / \mathrm{dl}$, and this is equivalent to $4.4-5.2 \mathrm{mEq} / \mathrm{l}$ or 2.2-2.6 $\mathrm{mmol} / \mathrm{l}[1]$. To convert from $\mathrm{mmol} / \mathrm{l}$ to $\mathrm{mEq} / \mathrm{l}$, multiply by +2 , which is the valence of calcium. To convert from $\mathrm{mmol} / \mathrm{l}$ to $\mathrm{mg} / \mathrm{dl}$, multiply by 40 (the atomic weight of $\mathrm{Ca}^{+2}$ ) and divide by 10 (i.e., multiply by 4). The normal value for ionized $\mathrm{Ca}^{+2}$ is about half of total serum $\mathrm{Ca}^{+2}, 4.4-5.2 \mathrm{mg} / \mathrm{dl}, 2.2-2.6 \mathrm{mEq} / 1$, or 1.10$1.30 \mathrm{mmol} / \mathrm{l}$. Serum $\mathrm{Ca}^{+2}$ exists in three forms: ionized (free; $48 \%$ ), protein-bound (mostly to albumin and less to globulins; $45 \%$ ), and complexed (bound to citrate, oxalate, carbonate, and phosphate; $7 \%$ ), as shown in Figure 1. Both ionized and complexed $\mathrm{Ca}^{+2}$ are diffusible (ultrafilterable by the kidney), while proteinbound $\mathrm{Ca}^{+2}$ is not [2].

Review began $12 / 08 / 2020$ Review ended 12/25/2020 Published 01/01/2021

\section{(c) Copyright 2021}

Tinawi. This is an open access article distributed under the terms of the Creative Commons Attribution License CC-BY 4.0., which permits unrestricted use, distribution, and reproduction in any medium, provided the original author and source are credited.

\section{Serum Ca}

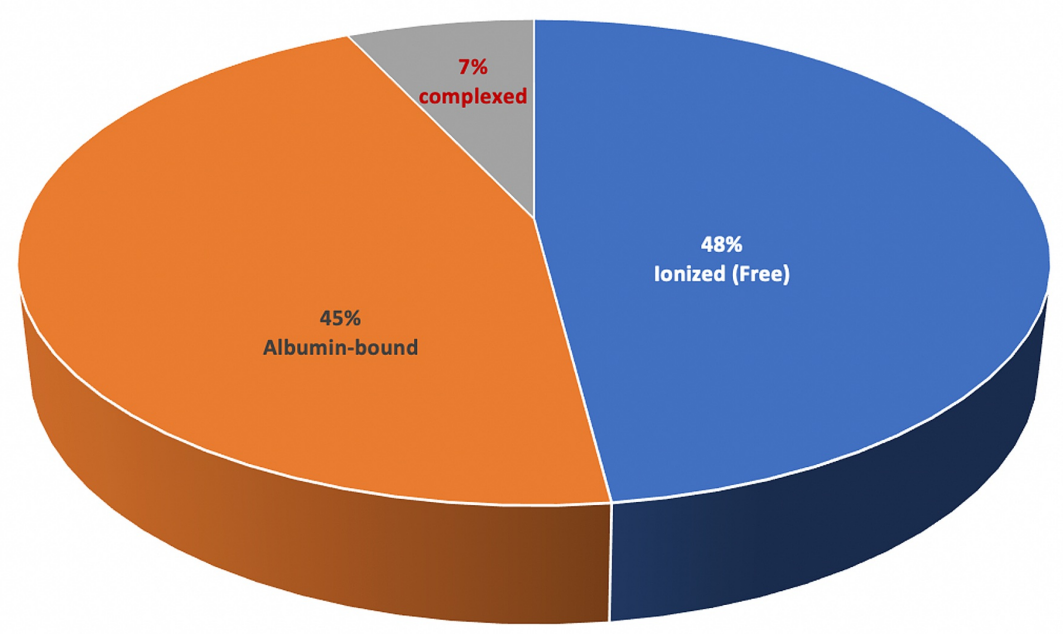




\section{FIGURE 1: The three different forms of serum calcium}

Complexed calcium is bound to anions such as citrate, oxalate, carbonate, and phosphate

Intracellular $\mathrm{Ca}^{+2}$ is bound to calmodulin and other $\mathrm{Ca}^{+2}$-binding proteins. Hypoalbuminemia will lead to hypocalcemia due to a decrease in protein-bound $\mathrm{Ca}^{+2}$. To correct for hypoalbuminemia, the following formula is used:

Corrected total serum $\mathrm{Ca}^{+2}(\mathrm{mg} / \mathrm{dl})=$ measured serum $\mathrm{Ca}^{+2}(\mathrm{mg} / \mathrm{dl})+0.8(4.0-$ serum albumin g/dl).

For example, if serum $\mathrm{Ca}^{+2}$ is $7.8 \mathrm{mg} / \mathrm{dl}$ and serum albumin is $2.5 \mathrm{~g} / \mathrm{dl}$, corrected serum $\mathrm{Ca}^{+2}=7.8+0.8(4.0$ $2.5)=9.0 \mathrm{mg} / \mathrm{dl}$; therefore, total serum $\mathrm{Ca}^{+2}$ is normal in this case and does not require replacement. Similarly, an increase in albumin by $1.0 \mathrm{~g} / \mathrm{dl}$ will lead to a $0.8 \mathrm{mg} / \mathrm{dl}$ increase in total serum $\mathrm{Ca}^{+2}$. This equation is not always accurate, especially in patients with stage 3-5 chronic kidney disease (CKD) [3]. Ionized $\mathrm{Ca}^{+2}$ should be checked whenever feasible to ascertain the diagnosis of hypocalcemia or hypercalcemia.

\section{Calcium distribution in the body}

The human body contains about $1,000-1,300 \mathrm{~g}$ of $\mathrm{Ca}^{+2}$, making $\mathrm{Ca}^{+2}$ the fifth most abundant element in the body [1]. About $99.3 \%$ of total body $\mathrm{Ca}^{+2}$ is in the bone (skeleton) and teeth, $0.6 \%$ is in soft tissues, and $0.1 \%$ resides in the extracellular fluid (ECF), including $0.03 \%$ in plasma [4]. Intracellular $\mathrm{Ca}^{+2}$ concentration is very low (about $100 \mathrm{nM}$ ), yet it is essential for several critical functions such as signal transduction, nerve conduction, muscle contraction, and blood coagulation. $\mathrm{Ca}^{+2}$ in the skeleton is complexed with phosphorus mainly as hydroxyapatite, which gives the bone its mechanical characteristics. It is important to know that only $1 \%$ of $\mathrm{Ca}^{+2}$ in the bone can immediately equilibrate with extracellular $\mathrm{Ca}^{+2}$.

\section{Incidence and prevalence of calcium metabolism disorders}

Hypercalcemia is fairly common with a prevalence of approximately $1-4 \%$ in the general population and $0.17-3 \%$ in hospitalized populations [4]. Hypocalcemia is significantly more prevalent in hospitalized patients (10-18\%). In those hospitalized in the intensive care unit, the prevalence of hypocalcemia can be as high as 70-80\% [4]. It is important to also recognize that the prevalence of hypomagnesemia in the intensive care setting is as high as $65 \%$, which contributes to the high prevalence of hypocalcemia in this patient population.

\section{Review}

\section{Calcium homeostasis}

Intestinal Absorption of Calcium

The average daily intake of $\mathrm{Ca}^{+2}$ is about $1,000 \mathrm{mg}$, of which $400 \mathrm{mg}$ is absorbed in the small intestine. About $200 \mathrm{mg}$ is excreted with intestinal secretions. Therefore, net absorption is $200 \mathrm{mg}$ (about 20\%); the remaining $800 \mathrm{mg}$ is excreted in the stool [2]. About $500 \mathrm{mg}$ of $\mathrm{Ca}^{+2}$ are exchanged daily between the bone and the ECF. Of the 10,000 $\mathrm{mg}$ of $\mathrm{Ca}^{+2}$ filtered through the kidneys, 9,800 $\mathrm{mg}$ (98\%) are reabsorbed by the renal tubules, and approximately $200 \mathrm{mg}$ are excreted, which equals the net amount absorbed in the small intestine (Figure 2). 


\section{Cureus}

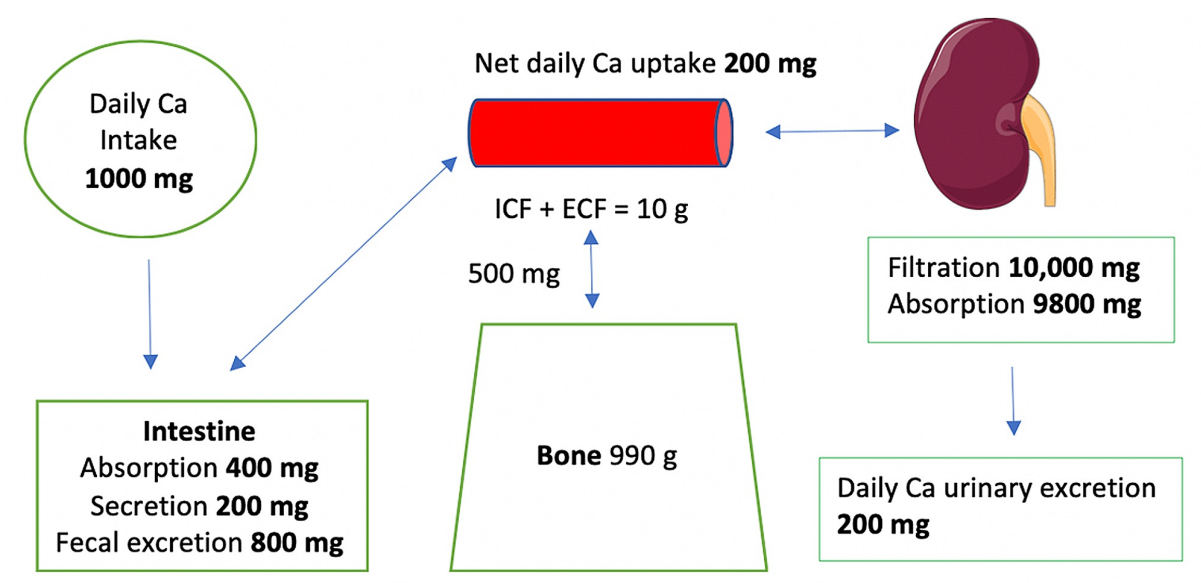

\section{FIGURE 2: Calcium homeostasis}

Approximately $500 \mathrm{mg}$ of calcium is exchanged daily between the ECF and the bone

ICF: intracellular fluid; ECF: extracellular fluid

Image of the kidney is courtesy of Servier Medical Art licensed under a Creative Commons Attribution 3.0 Unported License. https://smart.servier.com

In the small intestine, $\mathrm{Ca}^{+2}$ is absorbed both paracellularly (passive absorption through tight junctions) and transcellularly (active absorption). Paracellular absorption dominates when $\mathrm{Ca}^{+2}$ intake is high, while transcellular absorption dominates when $\mathrm{Ca}^{+2}$ intake is low [1]. Active absorption of $\mathrm{Ca}^{+2}$ is under the control of calcitriol $\left[1,25(\mathrm{OH})_{2} \mathrm{D}\right]$. Transcellular $\mathrm{Ca}^{+2}$ absorption occurs via two epithelial $\mathrm{Ca}^{+2}$ channels that belong to the transient receptor potential (TRP) superfamily and specifically to the vanilloid subfamily (TRPV) [5]. These two channels are transient receptor potential vanilloid 5 (TRPV5; pronounced trip V5) and TRPV6. Free $\mathrm{Ca}^{+2}$ exits the cell via the sodium-calcium $\left(\mathrm{Na}^{+}-\mathrm{Ca}^{+2}\right)$ exchanger.

Hormonal Regulation of Calcium Homeostasis

$\mathrm{Ca}^{+2}$ homeostasis is dependent on three processes: intestinal absorption, bone turnover $\left(\mathrm{Ca}^{+2}\right.$ exchange with the bone), and renal reabsorption [1]. The hormonal regulators of these processes are the parathyroid hormone $(\mathrm{PTH})$, calcitriol $\left[1,25(\mathrm{OH})_{2} \mathrm{D}\right]$, which is the most active form of vitamin $\mathrm{D}$, and serum ionized $\mathrm{Ca}^{+2}$. The receptors for these hormonal regulators are the PTH receptor (PTHR), the vitamin D receptor (VDR), and the calcium-sensing receptor (CaSR) respectively [6].

The Calcium-Sensing Receptor (CaSR)

The CaSR is a G protein-coupled receptor that regulates PTH secretion from the parathyroid glands. The CaSR senses extracellular ionized $\mathrm{Ca}^{+2}$. When serum $\mathrm{Ca}^{+2}$ is high, the CaSR is activated with a subsequent increase in renal $\mathrm{Ca}^{+2}$ excretion (calciuria) and inhibition of PTH secretion [7]. PTH inhibition decreases the release of $\mathrm{Ca}^{+2}$ from the bone and inhibits the synthesis of calcitriol. Inhibition of calcitriol synthesis also reduces mobilization of $\mathrm{Ca}^{+2}$ from bone and decreases active intestinal absorption of $\mathrm{Ca}^{+2}$. These effects will help in restoring $\mathrm{Ca}^{+2}$ towards normal levels [8]. The opposite effect is seen when serum $\mathrm{Ca}^{+2}$ is low. The CaSR is inactivated with a subsequent decrease in renal $\mathrm{Ca}^{+2}$ excretion and an increase in PTH secretion. PTH stimulation increases the release of $\mathrm{Ca}^{+2}$ from the bone and enhances the synthesis of calcitriol. Calcitriol mobilizes $\mathrm{Ca}^{+2}$ from the bone and increases active $\mathrm{Ca}^{+2}$ absorption in the intestine. These effects will help in restoring $\mathrm{Ca}^{+2}$ towards normal levels [9]. The CaSR is also expressed in the basolateral membranes of the thick ascending limb (TAL) of the loop of Henle.

Renal Calcium Handling

In the kidney, the proximal tubule (PT) reabsorbs $60-70 \%$ of filtered $\mathrm{Ca}^{+2}$, the TAL reabsorbs $20 \%$, the distal convoluted tubule (DCT) reabsorbs $10 \%$, and the collecting duct (CD) reabsorbs 5\% [2]. Regulation

of $\mathrm{Ca}^{+2}$ excretion in the kidney occurs at the terminal nephron. $\mathrm{Ca}^{+2}$ reabsorption in the $\mathrm{PT}$ is $85 \%$ via the 


\section{Cureus}

paracellular route (passive) [10]. Active transport via the apical membrane (transcellular) is responsible for the remaining $15 \%$ and is enhanced by calcitonin and PTH. In the TAL, absorption is both paracellular and transcellular but mostly paracellular [11]. As in the PT, transcellular (active) $\mathrm{Ca}^{+2}$ transport in the TAL is enhanced by calcitonin and PTH. Claudin-16 interacts with claudin-19 (both are tight junction proteins) forming a cation-selective tight junction protein complex that enables paracellular $\mathrm{Ca}^{+2}\left(\mathrm{and} \mathrm{Mg}^{+2}\right)$ transport in the TAL (Figure 3).

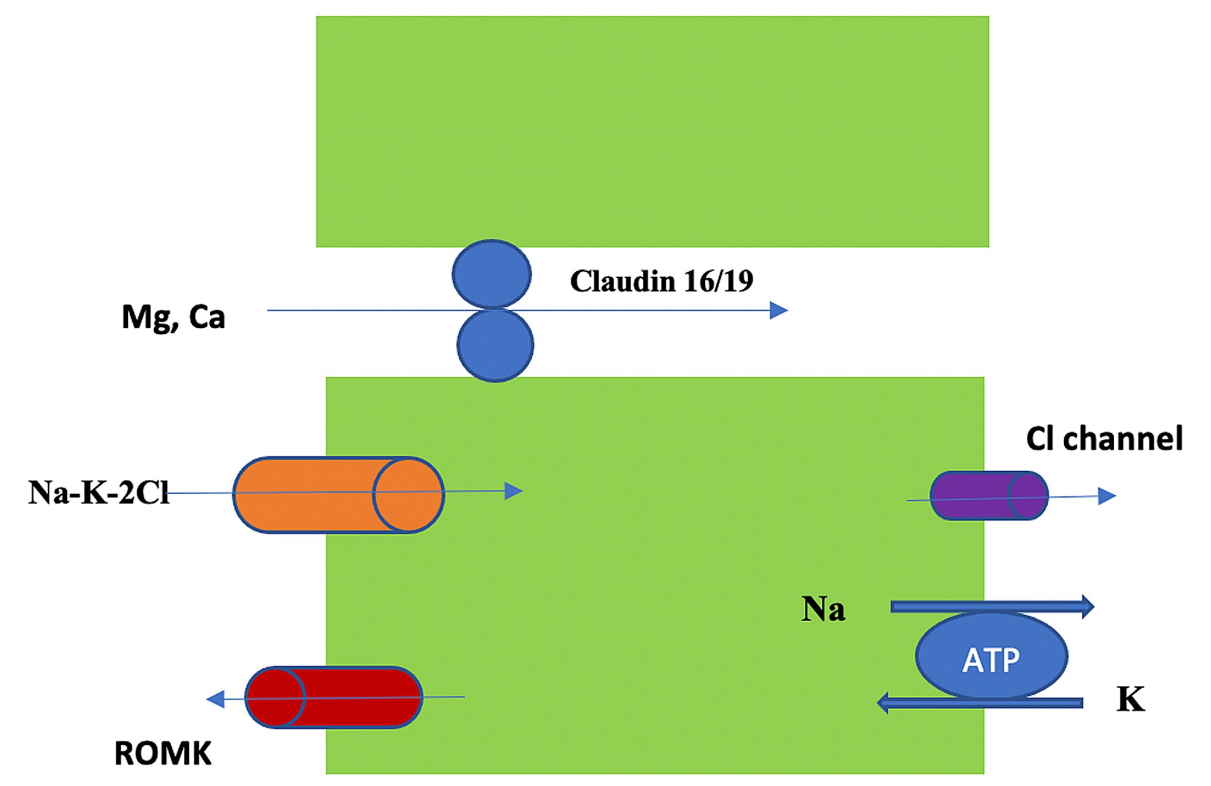

\section{FIGURE 3: Calcium and magnesium reabsorption in the TAL via the paracellular route}

The process is passive and depends on sodium and potassium uptake via the $\mathrm{Na}-\mathrm{K}-2 \mathrm{Cl}$ pump

Na-K-2Cl: sodium-potassium-2 chloride pump; ROMK: the renal outer medullary potassium channel; TIL: thick ascending limb; ATP: adenosine triphosphate

Courtesy of Tinawi M, Disorders of Magnesium Metabolism: Hypomagnesemia and Hypermagnesemia. Arch Clin Biomed Res, 4(3): 205-220, 2020; an open-access article distributed under the terms and conditions of the Creative Commons Attribution (CC-BY) license 4.0

Claudin-14 blocks paracellular $\mathrm{Ca}^{+2}$ reabsorption in the TAL in response to increased serum $\mathrm{Ca}^{+2}$ level [12]. $\mathrm{Ca}^{+2}$ reabsorption in the DCT is entirely active via the transcellular route through TRPV5 channels [13]. Hormonal regulations of $\mathrm{Ca}^{+2}$ and phosphate are tightly linked, while there is no hormonal system that significantly controls $\mathrm{Mg}^{+2}$ metabolism [14]. Phosphate homeostasis is regulated by PTH, calcitriol, fibroblast growth factor 23 (FGF-23), and FGF/Klotho receptor complex [2]. FGF-23 is secreted from the bone in response to an increase in serum phosphate level. It results in phosphaturia and a decrease in calcitriol production with a subsequent decrease in intestinal phosphate $\left(\right.$ and $\left.\mathrm{Ca}^{+2}\right)$ absorption. Increased PTH secretion leads to phosphaturia. While both PTH and FGF-23 are phosphaturic, they have the opposite effect on calcitriol (FGF-23 decreases and PTH increases the renal production of calcitriol).

\section{Parathyroid Hormone (PTH)}

PTH is the main regulator of renal $\mathrm{Ca}^{+2}$ reabsorption. A decrease in serum ionized $\mathrm{Ca}^{+2}$ (hypocalcemia) inactivates the CaSR in the parathyroid glands and subsequently stimulates PTH secretion. PTH and calcitriol enhance renal $\mathrm{Ca}^{+2}$ reabsorption in the DCT via the transcellular (active) route [13]. Moreover, PTH stimulates bone resorption by the osteoclasts and increases the secretion of calcitriol, which in turn stimulates intestinal $\mathrm{Ca}^{+2}$ and phosphate absorption by activating the VDR. Conversely, hypercalcemia decreases PTH secretion by activating the CaSR and the above actions are reversed. The hormonal response keeps serum $\mathrm{Ca}^{+2}$ in a narrow physiologic range [1]. Therefore, the function of the CaSR in the parathyroid glands is to change PTH secretion depending on serum ionized $\mathrm{Ca}^{+2}$ level. Both $\mathrm{Mg}^{+2}$ and Ca $\mathrm{Ca}^{+2}$ bind to the CaSR in the parathyroid glands and the kidney; however, each has a distinct binding site. $\mathrm{Mg}^{+2}$ plays a role in PTH modulation by acting on the CaSR $[15,16]$. PTH secretion is stimulated in acute hypomagnesemia and 


\section{Cureus}

suppressed in hypermagnesemia. It is important to note that profound hypomagnesemia suppresses (rather than stimulates) PTH secretion and increases PTH resistance in the bone leading to hypocalcemia $[9,10]$.

Vitamin $D$

Calcitriol is the most active form of vitamin $\mathrm{D}$ and is produced by tubular renal cells. 25 -hydroxyvitamin $\mathrm{D}$ $[25(\mathrm{OH}) \mathrm{D}]$ is produced in the liver and is converted to calcitriol by $1 \alpha$-hydroxylase $[3,8,17]$. Calcitriol enhances intestinal $\mathrm{Ca}^{+2}$ and phosphate absorption in addition to renal $\mathrm{Ca}^{+2}$ reabsorption in the DCT.

\section{Renal Calcium Reabsorption}

Volume expansion increases urine $\mathrm{Na}^{+}$and $\mathrm{Cl}^{-}$excretion and subsequently decreases renal $\mathrm{Ca}^{+2}$ absorption and the reverse is true in volume contraction. In metabolic alkalosis, bound hydrogen ions dissociate from albumin, which increases the fraction of albumin available for ionized $\mathrm{Ca}^{+2}$ binding [2]. Therefore, metabolic alkalosis leads to hypocalcemia. Acute and chronic metabolic acidosis leads to hypercalcemia because hydrogen is buffered in the bone with subsequent release of $\mathrm{Ca}^{+2}$ and calcinuria. Ionized $\mathrm{Ca}^{+2}$ changes by $0.12 \mathrm{mg} / \mathrm{dl}$ for each 0.1 change in $\mathrm{pH}$. Inhibition of the sodium-potassium chloride cotransporter 2 (NKCC2) in the loop of Henle by loop diuretics enhances $\mathrm{Ca}^{+2}$ excretion in the urine [8]. Thiazide diuretics are associated with hypercalcemia and hypocalciuria due to enhanced $\mathrm{Ca}^{+2}$ reabsorption in the PT (following $\mathrm{Na}+$ and water reabsorption due to volume contraction) and in the DCT (Table 1).

Factors that increase renal Ca reabsorption

Calcitriol

Hyperparathyroidism (increased PTH)

Hypocalcemia

Metabolic alkalosis

Thiazide diuretics, amiloride

Hypovolemia
Factors that decrease renal Ca reabsorption

\section{Calcitriol deficiency}

Hypoparathyroidism (decreased PTH)

Hypercalcemia

Metabolic acidosis and respiratory acidosis

Loop diuretics, mannitol

Hypervolemia

TABLE 1: Factors affecting renal calcium reabsorption

PTH: parathyroid hormone

Hypercalcemia increases calcitonin production by the $\mathrm{C}$ cells in the thyroid gland. Calcitonin inhibits bone resorption by the osteoclasts and increases renal $\mathrm{Ca}^{+2}$ and phosphate excretion [18]. Hypercalcemia activates CaSR in the basolateral membrane of the TAL. CaSR inhibits the renal outer medullary potassium channel (ROMK), which in turn inhibits $\mathrm{K}^{+}$recycling in the TAL; subsequently, the activity of the NKCC2 is decreased, which lowers the positive transepithelial voltage. The final outcome of this sequence of events is a decrease in paracellular transport of $\mathrm{Na}^{+}, \mathrm{Mg}^{+2}$, and $\mathrm{Ca}^{+2}$ (increased urinary excretion of $\mathrm{Na}^{+}$, $\mathrm{Mg}^{+2}$, and $\mathrm{Ca}^{+2}$ ) [2]. This explains why severe hypercalcemia leads to volume depletion and why normal saline (and not loop diuretics that lead to further volume depletion) is the first step in the management of severe hypercalcemia.

\section{Hypocalcemia}

Hypocalcemia is defined as serum $\mathrm{Ca}^{+2}$ of $<8.8 \mathrm{mg} / \mathrm{dl}(2.2 \mathrm{mmol} / \mathrm{l}$ or $4.4 \mathrm{mEq} / \mathrm{l})$. Hypocalcemia is easily diagnosed because $\mathrm{Ca}^{+2}$ is included in routine chemistry panels. As in hypercalcemia, $\mathrm{Ca}^{+2}$ should be corrected in case of hypoalbuminemia or hyperalbuminemia. It is preferable to obtain ionized $\mathrm{Ca}^{+2}$ to ascertain the diagnosis, especially in critically ill patients in whom $\mathrm{pH}$ variation changes $\mathrm{Ca}^{+2}$ binding to albumin [19]. As mentioned above, metabolic alkalosis increases $\mathrm{Ca}^{+2}$ binding to albumin and decreases ionized $\mathrm{Ca}^{+2}$. Hypocalcemia stimulates PTH release, which increases renal production of calcitriol; both hormones increase serum $\mathrm{Ca}^{+2}$ by the mechanism mentioned above.

Etiology

Hypocalcemia is more common than hypercalcemia in hospitalized patients. PTH can be low, normal, or 


\section{Cureus}

high. Hypocalcemia due to PTH deficiency is associated with low or low normal PTH and hyperphosphatemia, while other causes are associated with high PTH. Vitamin D deficiency, acute pancreatitis, hungry bone syndrome, and $\mathrm{Mg}^{+2}$ deficiency cause hypocalcemia with normal or low serum phosphate [8]. The hungry bone syndrome is seen post parathyroidectomy in patients with severe primary hyperparathyroidism. The most common causes of hypocalcemia are listed in Table 2.

Causes

PTH deficiency: hereditary (e.g., isolated congenital hypoparathyroidism, DiGeorge syndrome) or acquired hypoparathyroidism, postparathyroidectomy and post-thyroidectomy, post-parathyroid glands radiation

Vitamin D deficiency or resistance [lack of sun exposure, inadequate dietary intake, intestinal malabsorption (steatorrhea), hepatic disease, CKD, osteomalacia, rickets]

Increased $\mathrm{Ca}^{+2}$ uptake as in rhabdomyolysis, tumor lysis syndrome, hungry bone syndrome (post-parathyroidectomy), or acute pancreatitis

$\mathrm{Ca}^{+2}$ malabsorption due to small bowel pathologies such as short bowel syndrome and sprue

Acute hyperventilation (which results in respiratory alkalosis)

Low dietary intake of $\mathrm{Ca}^{+2}$ (rare in the absence of intestinal malabsorption or vitamin $\mathrm{D}$ deficiency)

Osteoclastic bone metastases as in prostate cancer and small cell lung cancer

Pseudohypoparathyroidism, which is a rare genetic disorder characterized by resistance to PTH actions

Hypermagnesemia and profound hypomagnesemia (due to suppression of PTH secretion)

Acute severe hyperphosphatemia

Intake of $\mathrm{Ca}^{+2}$-binding ingredients such as oxalate, phosphate, and cellulose

Medications: bisphosphonate, denosumab, cinacalcet, etelcalcetide

Massive blood transfusion due to binding of ionized $\mathrm{Ca}^{+2}$ with citrate

Critical illness

Pseudohypocalcemia caused by some gadolinium contrast agents (e.g., gadoversetamide) due to interference with total calcium laboratory assay

\section{TABLE 2: Causes of hypocalcemia}

PTH: parathyroid hormone; CKD: chronic kidney disease

Primary hypoparathyroidism can be due to antibodies against the parathyroid glands or activating antibodies against the CaSR. In either case, hypocalcemia ensues. Transient or permanent hypoparathyroidism can occur post thyroidectomy [20]. Activating mutations of the CaSR result in hereditary hypoparathyroidism, which is characterized by marked hypercalciuria [21]. Many patients with advanced CKD have secondary hyperparathyroidism (high PTH) and unlike primary hyperparathyroidism; they have low or low normal $\mathrm{Ca}^{+2}$ due to calcitriol deficiency. High doses of vitamin D will cause hypercalcemia in advanced CKD patients. Therefore, in CKD patients, $\mathrm{Ca}^{+2}$ can be low, normal, or high, and in many patients with advanced CKD (stages 4 and 5 and patients on dialysis), serum phosphate is high even in the presence of vitamin D deficiency. Both cinacalcet and etelcalcetide are calcimimetics (positive allosteric CaSR modulators) approved for the treatment of secondary hyperparathyroidism in dialysis patients. Both medications can cause hypocalcemia. One study has found hypocalcemia in $55 \%$ of patients admitted to the critical care unit of a tertiary care center [22]. Critical illness hypocalcemia is multifactorial and is attributed to vitamin D deficiency, abnormal PTH secretion and action, circulating catecholamines, medication adverse effects, and citrated blood transfusion.

\section{Manifestations}

Most patients with chronic hypocalcemia are asymptomatic. The clinical manifestations of hypocalcemia are a function of its severity and rapidity of onset. Hypocalcemia can manifest with muscle weakness, fatigue, confusion, depression, and memory loss [8]. Severe manifestations are seen in acute hypocalcemia and 
include seizures, tetany, paresthesias, laryngospasm, anxiety, and QT interval prolongation. Trousseau's sign (carpopedal spasm) is carpal spasm during blood pressure measurement when the cuff is kept inflated over the systolic blood pressure for three minutes, resulting in forearm ischemia [23]. Chvostek's sign is facial muscle twitching when the facial nerve is tapped near the jaw angle about $2 \mathrm{~cm}$ anterior to the earlobe. Both signs are due to neuromuscular excitability. Chronic hypocalcemia, as in hypoparathyroidism, can be associated with dry keratotic skin, ridged nails, and course brittle hair [24].

Evaluation

In addition to serum $\mathrm{Ca}^{+2}$, albumin, and ionized $\mathrm{Ca}^{+2}$, other electrolytes, especially phosphate and $\mathrm{Mg}^{+2}$, are measured. ECG is needed in severe hypocalcemia. Further evaluation includes measurement of urea, creatinine, PTH, 25(OH)D, 1,25(OH $)_{2} \mathrm{D}$, and 24-hour urinary $\mathrm{Ca}^{+2}$ and phosphate. Patients with elevated PTH and creatinine due to CKD can have hypocalcemia associated with secondary hyperparathyroidism. Low PTH points toward hypoparathyroidism. If PTH is elevated (the expected response to hypocalcemia), and $25(\mathrm{OH}) \mathrm{D}$ is low, the patient has vitamin D deficiency. Patients with vitamin D-dependent and vitamin Dresistant rickets have elevated PTH and normal 25(OH)D levels [4].

Management

Symptomatic patients (usually $\mathrm{Ca}^{+2}$ of $<7.6 \mathrm{mg} / \mathrm{dl}$ or $1.9 \mathrm{mmol} / \mathrm{l}$; ionized $\mathrm{Ca}^{+2}$ of $<1 \mathrm{mmol} / \mathrm{l}$ ) are treated with intravenous Ca gluconate $(93 \mathrm{mg}$ or $2.32 \mathrm{mmol}$ elemental $\mathrm{Ca} / 1 \mathrm{~g})$. Ca chloride ( $273 \mathrm{mg}$ or $6.80 \mathrm{mmol}$ elemental $\mathrm{Ca} / \mathrm{g}$ ) can be given if central venous access is available. Cardiac monitoring is recommended during intravenous $\mathrm{Ca}^{+2}$ replacement, especially in patients on digoxin [25]. Asymptomatic patients are treated with oral $\mathrm{Ca}^{+2}$ supplements, usually Ca carbonate or Ca citrate; $1 \mathrm{~g}$ of Ca carbonate contains $400 \mathrm{mg}$ of elemental Ca (40\%), while $1 \mathrm{~g}$ of Ca citrate contains $211 \mathrm{mg}$ of elemental $\mathrm{Ca}(21 \%)$. Ca acetate is used as a phosphate binder in patients with CKD. Vitamin D should be replaced if deficient [23]. Either vitamin D2 (ergocalciferol) or D3 (cholecalciferol) can be given. Oral calcitriol at a dose of $0.25-1 \mathrm{mcg} /$ day is particularly helpful. Hypomagnesemia should be corrected. Hyperphosphatemia in patients with hypoparathyroidism is managed with a low phosphate diet and phosphate binders. In patients with

hypoparathyroidism, $\mathrm{Ca}^{+2}$ should be kept in the low normal range because overtreatment with $\mathrm{Ca}^{+2}$ and vitamin D supplementations will lead to hypercalciuria, nephrolithiasis, nephrocalcinosis, and soft-tissue calcifications [23]. Recombinant human parathyroid hormone (rhPTH 1-84, Natpara) is approved in the US for the management of hypocalcemia in hypoparathyroidism in addition to $\mathrm{Ca}^{+2}$ and vitamin $\mathrm{D}$ [26]. However, its distribution is restricted. It has a black box warning due to the potential risk of osteosarcoma. Thiazide diuretics lower urinary $\mathrm{Ca}^{+2}$ excretion and may be helpful in patients with hypercalciuria.

\section{Hypercalcemia}

Hypercalcemia is defined as serum $\mathrm{Ca}^{+2}$ of level $>10.4 \mathrm{mg} / \mathrm{dl}(2.6 \mathrm{mmol} / \mathrm{l}$ or $5.2 \mathrm{mEq} / \mathrm{l})$. Hypercalcemia can be mild $\left(\mathrm{Ca}^{+2}\right.$ of $\left.10.5-11.9 \mathrm{mg} / \mathrm{dl}\right)$, moderate $\left(\mathrm{Ca}^{+2}\right.$ of $\left.12-13.9 \mathrm{mg} / \mathrm{dl}\right)$, or severe (hypercalcemic crisis; $\mathrm{Ca}^{+2}$ of $\geqslant 14 \mathrm{mg} / \mathrm{dl}$ ) [18]. Patients with mild hypercalcemia are often asymptomatic.

\section{Manifestations}

Symptoms are non-specific and may overlap with other electrolyte disorders. As in hypocalcemia, the clinical manifestations of hypercalcemia are a function of its severity and rapidity of onset. The symptoms include fatigue, weakness, anxiety, and increased sleepiness. This is followed by nausea, vomiting, abdominal pain, and constipation. Renal manifestations include polyuria, kidney stones, and nephrocalcinosis. Other manifestations include bone pain, headache, hypertension, shortened QT interval, and rarely, stupor and coma [18]. Severe acute hypercalcemia can result in acute kidney injury (AKI) (due to severe dehydration), nephrogenic diabetes insipidus (NDI), and cardiac arrhythmias [4]. Someone has proposed the mnemonic "stones, bones, abdominal moans and psychic groans" to remember the manifestations of hypercalcemia.

Etiology

Hypercalcemia is most commonly caused by enhanced bone resorption; it can also result from enhanced intestinal absorption or decreased renal $\mathrm{Ca}^{+2}$ excretion (Table 3). 


\section{Cureus}

\section{Causes}

PTH excess (primary hyperparathyroidism) due to parathyroid gland adenoma ( $80 \%$ of cases) or hyperplasia (10-15\% of cases). Primary hyperparathyroidism is part of the multiple endocrine neoplasia (MEN) 1 and 2A. Parathyroid carcinoma is rare

Humoral hypercalcemia of malignancy

Osteolytic bone metastases as in multiple myeloma, and metastatic breast and lung cancers

Milk-alkali syndrome (increased intestinal absorption of $\mathrm{Ca}^{+2}$ due to excessive intake of $\mathrm{Ca}^{+2}$, antacids, and vitamin D) 25(OH)D toxicity (usually due to excess intake of over-the-counter supplements)

$1,25(\mathrm{OH})_{2} \mathrm{D}$ excess as in excessive intake, lymphoma, and granulomatous disorders such as sarcoidosis, tuberculosis, leprosy, berylliosis, histoplasmosis, and Farmer's lung

Immobilization

Paget's disease

Thyrotoxicosis, acromegaly, pheochromocytoma, acute adrenal insufficiency

Thiazide diuretics (hypercalcemia is usually mild, and hyperparathyroidism should be excluded), lithium, theophylline, growth hormone, recombinant human PTH (teriparatide), and hyperalimentation solutions

Adynamic bone disease (decreased bone formation) as in patients with end-stage renal disease (ESRD) due to the inability of the bone to take up $\mathrm{Ca}^{+2}$

Excess intake of dietary $\mathrm{Ca}^{+2}$ in patients with $\mathrm{CKD}$ and in children

Vitamin A toxicity (hypervitaminosis A)

Neonatal severe hyperparathyroidism (homozygous CaSR-inactivating mutations)

Familial hypocalciuric hypercalcemia $(\mathrm{FHH})$, which is due to heterozygous CaSR-inactivating mutations

Hypercalcemia of pregnancy (uncommon) due to the production of PTHrP

\section{TABLE 3: Causes of hypercalcemia}

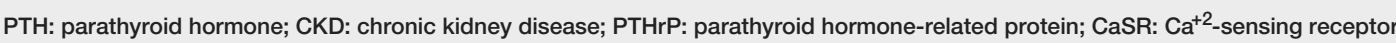

Most patients with hypercalcemia have either primary hyperparathyroidism or malignancy. Primary hyperparathyroidism predominates in ambulatory patients with hypercalcemia, while malignancies predominate in hospitalized patients. Hypercalcemia in the course of a malignancy carries a poor prognosis [27]. Hypercalcemia can be the first clue to the presence of an occult malignancy. The incidence of hypercalcemia in cancer patients is as high as $30 \%$ [28]. Primary hyperparathyroidism and malignancy are responsible for $80-90 \%$ of hypercalcemia cases [28]. Malignancy-associated hypercalcemia can be severe and occasionally life-threatening [29]. It is either humoral or due to osteolytic bone metastases. Humoral hypercalcemia of malignancy is responsible for $80 \%$ of hypercalcemia due to malignancy. It is mediated by parathyroid hormone-related protein (PTHrP), which enhances osteoclastic activity [30]. Examples include renal cell carcinoma, adenocarcinoma of the ovary and breast, and squamous cell carcinoma of the lung, esophagus, and cervix [31]. PTHrP has the same effect as PTH on target cells and both hormones have a common receptor [8]. Inactivating mutations in the CaSR are the cause of neonatal severe

hyperparathyroidism in the case of homozygous mutations, and familial hypocalciuric hypercalcemia (FHH) in the case of heterozygous mutations [7]. Inactivating mutations of the CaSR mimic the effects of PTH. FHH is an autosomal dominant disorder associated with moderate hypercalcemia. FHH patients also have normal or moderately high PTH, hypophosphatemia, and hypermagnesemia. FHH does not result in severe symptomatic hypercalcemia. Milk-alkali syndrome (calcium-alkali syndrome) is caused by increased intestinal absorption of $\mathrm{Ca}^{+2}$ due to high intake of $\mathrm{Ca}^{+2}$ and vitamin D, especially when taken with antacids (alkali) [32,33]. It is associated with the kidneys' inability to excrete excess $\mathrm{Ca}^{+2}$. Patients can also have nephrocalcinosis [8]. The name of the syndrome comes from the practice of ingesting a large amount of milk that is high in $\mathrm{Ca}^{+2}$ for the treatment of peptic ulcer disease in the past when effective medications were unavailable. In some patients, the source of $\mathrm{Ca}^{+2}$ may not be immediately evident; for example, each piece of nicotine-substitute gum contains $94 \mathrm{mg}$ of elemental $\mathrm{Ca}^{+2}$.

Diagnosis 
Hypercalcemia is diagnosed when total serum $\mathrm{Ca}^{+2}$ is $>10.4 \mathrm{mg} / \mathrm{dl}$ and ionized $\mathrm{Ca}^{+2}$ is $>5.3$ $\mathrm{mg} / \mathrm{dl}[$ [4]. Hypercalcemia workup includes a detailed history and physical examination with emphasis on medications and supplementations including vitamin $\mathrm{D}$ and $\mathrm{Ca}^{+2}$. Hypercalcemia in primary hyperparathyroidism is chronic and usually mild and most patients are asymptomatic. Mild to moderate hypophosphatemia can be seen. Cervical ultrasound and 99mTc-sestamibi scintigraphy may help in the localization of parathyroid adenomas. A variant of primary hyperparathyroidism is named normocalcemic primary hyperparathyroidism due to normal serum $\mathrm{Ca}^{+2}$ and elevated PTH level [34]. The diagnosis of hypercalcemia is easily made because $\mathrm{Ca}^{+2}$ is included in routine chemistry panels. Measurement of other electrolytes such as $\mathrm{Na}^{+}, \mathrm{K}^{+}, \mathrm{Mg}^{+2}$, and phosphate in addition to renal function tests is needed. Serum $\mathrm{Ca}^{+2}$ should be corrected for albumin in cases of hypoalbuminemia or hyperalbuminemia. Measurement of ionized $\mathrm{Ca}^{+2}$ is preferable. A study by Obi et al. has reported that the majority of hemodialysis patients with high ionized Ca (hypercalcemia) will be misdiagnosed as normocalcemic if total serum $\mathrm{Ca}^{+2}$ (whether corrected for albumin or not) is measured [35]. The same authors have devised the following formula for calculating corrected total $\mathrm{Ca}^{+2}$ in hemodialysis patients [36]:

Corrected total serum $\mathrm{Ca}^{+2}(\mathrm{mg} / \mathrm{dL})=1.35 \mathrm{x}$ total serum $\mathrm{Ca}^{+2}(\mathrm{mg} / \mathrm{dL})-0.65 \mathrm{x}$ serum albumin $(\mathrm{g} / \mathrm{dL})-0.15 \mathrm{x}$ serum phosphorus $(\mathrm{mg} / \mathrm{dL})+0.3$.

Of note, the authors reported that patients with hidden hypercalcemia had a higher mortality rate when compared to patients with normal serum $\mathrm{Ca}^{+2}$ (ionized $\mathrm{Ca}^{+2}$ of 1.16-1.32 mmol/), [adjusted hazard ratio of approximately 1.75 (95\% confidence interval: $1.11-2.75)]$.

Once the diagnosis is ascertained, PTH should be measured. PTH is appropriately suppressed in all of the above conditions except primary hyperparathyroidism. It can be elevated in FHH as well. The further evaluation depends on suspected etiology. Measurement of 24-hour urine $\mathrm{Ca}^{+2}$ is critical in patients suspected of having primary hyperparathyroidism or FHH. If a 24-hour urine collection is not feasible, a random urine $\mathrm{Ca}^{+2} /$ creatinine ratio can be obtained. In hypercalciuria, the ratio is $>0.03$. Measurement of $\mathrm{PTHrP}$ is done in patients with known or suspected malignancy. Elevated alkaline phosphatase is seen in bone lysis. $1,25(\mathrm{OH})_{2} \mathrm{D}$ level is measured in patients suspected of having hypercalcemia due to sarcoidosis or lymphoma. $25(\mathrm{OH}) \mathrm{D}$ is measured if patient history raises the possibility of vitamin $\mathrm{D}$ toxicity. It is critical to distinguish primary hyperparathyroidism from FHH. In primary hyperparathyroidism, urinary $\mathrm{Ca}^{+2}$ is high ( $>200 \mathrm{mg}$ in 24-hour urine or urine $\mathrm{Ca}^{+2} /$ creatinine ratio of $>0.03$ ), while in FHH it is inappropriately normal or low (urine $\mathrm{Ca}^{+2} /$ creatinine ratio of $<0.02$ ) $[4,7]$. Genetic testing and detailed family history are needed to ascertain the diagnosis of $\mathrm{FHH}$.

Management

The most critical step in the management of severe hypercalcemia is volume repletion with $0.9 \%$ isotonic saline [37]. The value of loop diuretics in the management of severe hypercalcemia is questionable. Loop diuretics should never be given prior to volume repletion [38]. They may have a role in patients who develop hypervolemia [31]. Bisphosphonates (particularly intravenous zoledronate and pamidronate) are indicated for the treatment of malignancy-associated hypercalcemia [39]. This class of drugs inhibits bone resorption and $1,25(\mathrm{OH})_{2} \mathrm{D}$ synthesis. A complete response takes two to four days; hence, repeat administration over a short interval will lead to hypocalcemia. Bisphosphonates should be used with caution in patients with CKD. The dose should be lowered, and the infusion rate should be slowed [40]. For example, if a patient has CKD stage 4 , zoledronate can be given at a dose of $2 \mathrm{mg}$ (rather than the standard $4 \mathrm{mg}$ dose) over two hours (rather than the standard 15 minutes). Denosumab is a fully human monoclonal antibody that targets the receptor activator of NF-KB ligand (RANKL). It is an effective option for refractory hypercalcemia [41]. Denosumab can result in severe hypocalcemia especially in patients with advanced CKD. Calcitonin-Salmon is expensive and of limited value in the management of severe hypercalcemia [31]. It is given subcutaneously ( $\mathrm{SQ}$ ) or intramuscularly (IM). Tachyphylaxis develops quickly. Corticosteroids are particularly effective in hypercalcemia due to granulomatous diseases such as sarcoidosis because they inhibit the abnormal production of calcitriol [42]. Recalcitrant hypercalcemia, especially in patients with acute kidney injury or advanced CKD, will respond to hemodialysis utilizing a low $\mathrm{Ca}^{+2}$ dialysate bath of $\leqslant 2$ $\mathrm{mEq} / 1$ [43].

Once acute and severe hypercalcemia is treated, the underlying cause should be addressed. Patients with symptomatic primary hyperparathyroidism (nephrolithiasis, moderate or severe hypercalcemia, osteoporosis, fragility fractures, or hypercalciuria) are treated surgically with parathyroidectomy unless contraindicated [44]. Guidelines have been published regarding the management of asymptomatic primary hyperparathyroidism [45]. Cinacalcet (a calcimimetic drug that increases the sensitivity of CaSR to extracellular $\mathrm{Ca}^{+2}$ ) is routinely used in the chronic management of secondary hyperparathyroidism in patients on renal replacement therapy. It can also be used in patients with severe hypercalcemia due to primary hyperparathyroidism [46]. A five-year study in patients with mild to moderate primary 
hyperparathyroidism showed that cinacalcet reduced PTH level and normalized $\mathrm{Ca}^{+2}$ with no change in zscores of areal bone mineral density (aBMD) [47]. Cinacalcet was well-tolerated by the patients.

\section{Conclusions}

There are three $\mathrm{Ca}^{+2}$-regulating hormonal systems: PTH, vitamin D, and calcitonin. CaSR plays a critical role in $\mathrm{Ca}^{+2}$ homeostasis. $\mathrm{Ca}^{+2}$ level is maintained by the interplay between the above hormones and the bowel ( $\mathrm{Ca}^{+2}$ absorption), kidneys ( $\mathrm{Ca}^{+2}$ reabsorption and excretion), and bone $\left(\mathrm{Ca}^{+2}\right.$ uptake and release). The most common causes of hypocalcemia are PTH and vitamin D deficiencies, while the most common causes of hypercalcemia are primary hyperparathyroidism and malignancies. Hypercalcemia is frequently encountered in malignancies and carries a poor prognosis. Aggressive hydration and

bisphosphonates are the basis of treatment. Hypocalcemia is managed with the replacement of $\mathrm{Ca}^{+2}$, vitamin $\mathrm{D}$, and $\mathrm{Mg}$ (if indicated). However, excessive replacement of $\mathrm{Ca}^{+2}$ and vitamin $\mathrm{D}$ should be avoided.

\section{Additional Information \\ Disclosures}

Conflicts of interest: In compliance with the ICMJE uniform disclosure form, all authors declare the following: Payment/services info: All authors have declared that no financial support was received from any organization for the submitted work. Financial relationships: All authors have declared that they have no financial relationships at present or within the previous three years with any organizations that might have an interest in the submitted work. Other relationships: All authors have declared that there are no other relationships or activities that could appear to have influenced the submitted work.

\section{References}

1. Peacock M: Calcium metabolism in health and disease. Clin J Am Soc Nephrol. 2010, 5:S23-30. 10.2215/CJN.05910809

2. Blaine J, Chonchol M, Levi M: Renal control of calcium, phosphate, and magnesium homeostasis . Clin J Am Soc Nephrol. 2015, 10:1257-72. 10.2215/CJN.09750913

3. Gauci C, Moranne O, Fouqueray B, et al.: Pitfalls of measuring total blood calcium in patients with CKD . J Am Soc Nephrol. 2008, 19:1592-8. 10.1681/ASN.2007040449

4. Chonchol M, Smogorzewski M, Stubbs J, Yu AS: Disorders of calcium, magnesium, and phosphate balance . Brenner \& Rector's The Kidney. Yu AS, Chertow GM, Luyckx VA, Marsden PA, Skorecki K, Taal M (ed): Elsevier Inc, Philadelphia, PA; 2019. 11:613.

5. Pérez AV, Picotto G, Carpentieri AR, Rivoira MA, Peralta López ME, Tolosa de Talamoni NG: Minireview on regulation of intestinal calcium absorption. Emphasis on molecular mechanisms of transcellular pathway. Digestion. 2008, 77:22-34. 10.1159/000116623

6. Brown EM: The calcium-sensing receptor: physiology, pathophysiology and CaR-based therapeutics. Subcell Biochem. 2007, 45:139-67. 10.1007/978-1-4020-6191-2_6

7. Kuo E, Kemp EH, Sandhu HK, Brown EM, Weetman AP, Huang CL: Acquired hypocalciuric hypercalcemia in a patient with CKD. Am J Kidney Dis. 2013, 62:1151-4. 10.1053/j.ajkd.2013.04.023

8. Kestenbaum B, Houillier P: Disorders of calcium, phosphate, and magnesium metabolism . Comprehensive Clinical Nephrology. Johnson R, Feehally J, Floege J, Tonelli M (ed): Elsevier Inc, Philadelphia, PA; 2018. 6:124-41.

9. Riccardi D, Brown EM: Physiology and pathophysiology of the calcium-sensing receptor in the kidney . Am J Physiol Renal Physiol. 2010, 298:F485-99. 10.1152/ajprenal.00608.2009

10. Yu AS, Cheng MH, Angelow S, et al.: Molecular basis for cation selectivity in claudin-2-based paracellular pores: identification of an electrostatic interaction site. J Gen Physiol. 2009, 133:111-27. 10.1085/jgp.200810154

11. Sato T, Courbebaisse M, Ide N, et al.: Parathyroid hormone controls paracellular Ca $2+$ transport in the thick ascending limb by regulating the tight-junction protein Claudin14. Proc Natl Acad Sci U S A. 2017, 114:E3344-53. 10.1073/pnas.1616733114

12. Alexander RT, Rievaj J, Dimke H: Paracellular calcium transport across renal and intestinal epithelia. Biochem Cell Biol. 2014, 92:467-80. 10.1139/bcb-2014-0061

13. Dimke H, Hoenderop JG, Bindels RJ: Hereditary tubular transport disorders: implications for renal handling of Ca2+ and Mg2+. Clin Sci (Lond). 2009, 118:1-18. 10.1042/CS20090086

14. Tinawi M: Disorders of magnesium metabolism: hypomagnesemia and hypermagnesemia . Arch Clin Biomed Res. 2020, 4:205-20. 10.26502/acbr.50170099

15. Kumar R, Thompson JR: The regulation of parathyroid hormone secretion and synthesis . J Am Soc Nephrol. 2011, 22:216-24. 10.1681/ASN.2010020186

16. Martin KJ, González EA, Slatopolsky E: Clinical consequences and management of hypomagnesemia. J Am Soc Nephrol. 2009, 20:2291-5. 10.1681/ASN.2007111194

17. Christakos S, Dhawan P, Verstuyf A, Verlinden L, Carmeliet G: Vitamin D: metabolism, molecular mechanism of action, and pleiotropic effects. Physiol Rev. 2016, 96:365-408. 10.1152/physrev.00014.2015

18. Carroll MF, Schade DS: A practical approach to hypercalcemia. Am Fam Physician. 2003, 67:1959-66.

19. Dickerson RN, Henry NY, Miller PL, Minard G, Brown RO: Low serum total calcium concentration as a marker of low serum ionized calcium concentration in critically ill patients receiving specialized nutrition support. Nutr Clin Pract. 2007, 22:323-8. 10.1177/0115426507022003323

20. Ritter K, Elfenbein D, Schneider DF, Chen H, Sippel RS: Hypoparathyroidism after total thyroidectomy: incidence and resolution. J Surg Res. 2015, 197:348-53. 10.1016/j.jss.2015.04.059 
21. Lienhardt A, Bai M, Lagarde JP, et al.: Activating mutations of the calcium-sensing receptor: management of hypocalcemia. J Clin Endocrinol Metab. 2001, 86:5313-23. 10.1210/jcem.86.11.8016

22. Steele T, Kolamunnage-Dona R, Downey C, Toh CH, Welters I: Assessment and clinical course of hypocalcemia in critical illness. Crit Care. 2013, 17:R106. 10.1186/cc12756

23. Fong J, Khan A: Hypocalcemia: updates in diagnosis and management for primary care . Can Fam Physician. 2012, 58:158-62.

24. Fuleihan Gel-H, Rubeiz N: Dermatologic manifestations of parathyroid-related disorders. Clin Dermatol. 2006, 24:281-8. 10.1016/j.clindermatol.2006.04.003

25. Cooper MS, Gittoes NJ: Diagnosis and management of hypocalcaemia . BMJ. 2008, 336:1298-302. 10.1136/bmj.39582.589433.BE

26. Mannstadt M, Clarke BL, Vokes T, et al.: Efficacy and safety of recombinant human parathyroid hormone (184) in hypoparathyroidism (REPLACE): a double-blind, placebo-controlled, randomised, phase 3 study. Lancet Diabetes Endocrinol. 2013, 1:275-83. 10.1016/S2213-8587(13)70106-2

27. Ramos REO, Perez Mak M, Alves MFS, et al.: Malignancy-related hypercalcemia in advanced solid tumors: survival outcomes. J Glob Oncol. 2017, 3:728-33. 10.1200/JGO.2016.006890

28. Renaghan AD, Rosner MH: Hypercalcemia: etiology and management. Nephrol Dial Transpl. 2018, 33:54951. 10.1093/ndt/gfy054

29. Zagzag J, Hu MI, Fisher SB, Perrier ND: Hypercalcemia and cancer: differential diagnosis and treatment. CA Cancer J Clin. 2018, 68:377-86. 10.3322/caac.21489

30. Ratcliffe WA, Hutchesson AC, Bundred NJ, Ratcliffe JG: Role of assays for parathyroid-hormone-related protein in investigation of hypercalcaemia. Lancet. 1992, 339:164-7. 10.1016/0140-6736(92)90220-W

31. Rosner MH, Dalkin AC: Onco-nephrology: the pathophysiology and treatment of malignancy-associated hypercalcemia. Clin J Am Soc Nephrol. 2012, 7:1722-9. 10.2215/CJN.02470312

32. Felsenfeld AJ, Levine BS: Milk alkali syndrome and the dynamics of calcium homeostasis . Clin J Am Soc Nephrol. 2006, 1:641-54. 10.2215/CJN.01451005

33. Patel AM, Adeseun GA, Goldfarb S: Calcium-alkali syndrome in the modern era . Nutrients. 2013, 5:4880-93. 10.3390/nu5124880

34. Tuna MM, Çalışkan M, Ünal M, et al.: Normocalcemic hyperparathyroidism is associated with complications similar to those of hypercalcemic hyperparathyroidism. J Bone Miner Metab. 2016, 34:331-5. 10.1007/s00774-015-0673-3

35. Obi Y, Mehrotra R, Rivara MB, et al.: Hidden hypercalcemia and mortality risk in incident hemodialysis patients. J Clin Endocrinol Metab. 2016, 101:2440-9. 10.1210/jc.2016-1369

36. Obi Y, Nguyen DV, Streja E, et al.: Development and validation of a novel laboratory-specific correction equation for total serum calcium and its association with mortality among hemodialysis patients. J Bone Miner Res. 2017, 32:549-59. 10.1002/jbmr.3013

37. Stewart AF: Clinical practice. Hypercalcemia associated with cancer. N Engl J Med. 2005, 352:373-9. 10.1056/NEJMcp042806

38. LeGrand SB, Leskuski D, Zama I: Narrative review: furosemide for hypercalcemia: an unproven yet common practice. Ann Intern Med. 2008, 149:259-63. 10.7326/0003-4819-149-4-200808190-00007

39. Major P, Lortholary A, Hon J, et al.: Zoledronic acid is superior to pamidronate in the treatment of hypercalcemia of malignancy: a pooled analysis of two randomized, controlled clinical trials. J Clin Oncol. 2001, 19:558-67. 10.1200/JCO.2001.19.2.558

40. Toussaint ND, Elder GJ, Kerr PG: Bisphosphonates in chronic kidney disease; balancing potential benefits and adverse effects on bone and soft tissue. Clin J Am Soc Nephrol. 2009, 4:221-33. 10.2215/CJN.02550508

41. Cicci JD, Buie L, Bates J, van Deventer H: Denosumab for the management of hypercalcemia of malignancy in patients with multiple myeloma and renal dysfunction. Clin Lymphoma Myeloma Leuk. 2014, 14:e20711. 10.1016/j.clml.2014.07.005

42. Sandler LM, Winearls CG, Fraher LJ, Clemens TL, Smith R, O'Riordan JL: Studies of the hypercalcaemia of sarcoidosis: effect of steroids and exogenous vitamin D3 on the circulating concentrations of 1,25-dihydroxy vitamin D3. Q J Med. 1984, 53:165-80. 10.1093/oxfordjournals.qjmed.a067792

43. Camus C, Charasse C, Jouannic-Montier I, Seguin P, Tulzo YL, Bouget J, Thomas R: Calcium free hemodialysis: experience in the treatment of 33 patients with severe hypercalcemia. Intensive Care Med. 1996, 22:116-21. 10.1007/BF01720717

44. Insogna KL: Primary hyperparathyroidism. N Engl J Med. 2018, 379:1050-9. 10.1056/NEJMcp1714213

45. Bilezikian JP, Brandi ML, Eastell R, Silverberg SJ, Udelsman R, Marcocci C, Potts JT Jr: Guidelines for the management of asymptomatic primary hyperparathyroidism: summary statement from the Fourth International Workshop. J Clin Endocrinol Metab. 2014, 99:3561-9. 10.1210/jc.2014-1413

46. Peacock M, Bilezikian JP, Klassen PS, Guo MD, Turner SA, Shoback D: Cinacalcet hydrochloride maintains long-term normocalcemia in patients with primary hyperparathyroidism. J Clin Endocrinol Metab. 2005, 90:135-41. 10.1210/jc.2004-0842

47. Peacock M, Bolognese MA, Borofsky M, Scumpia S, Sterling LR, Cheng S, Shoback D: Cinacalcet treatment of primary hyperparathyroidism: biochemical and bone densitometric outcomes in a five-year study. J Clin Endocrinol Metab. 2009, 94:4860-7. 10.1210/jc.2009-1472 